\title{
Development of good practices database of European regions for prevention of work related musculoskeletal disorders: TIAM project
}

\author{
Achleitner H. *, Álvarez-Casado, E. **, Zhang, B. ** \\ *TZ PERG, Upper Austria, Email address: hannes.achleitner@tzperg.at \\ **Departament d'Organització d'Empreses (DOE), Escola Tècnica Superior d'Enginyeria Industrial de \\ Barcelona (ETSEIB), Universitat Politècnica de Catalunya (UPC), AV. Diagonal, 647 pl 7 - ETSEIB, \\ 08028 Barcelona, Spain, +34 9340544 69, Email address: enrique.alvarez@upc.edu, \\ bing.zhang@upc.edu
}

\begin{abstract}
Work-related musculoskeletal disorders (WMSDs) are extremely common health problem and have important consequences for the individual and the society which are affecting millions of European workers across all employment sectors. One of the main objectives of TIAM is to collect good practices in prevention of WMSDs and disseminate the good practice to all the regions. Three documents related to collect good practices (Good practices definition, Good practices report form and Questionnaire form for regional policy) had been sent to all the participant regions. Good practices and successful experiences or innovations in WMSDs prevention have been collected from 5 European regions. A good practice database has been developed based on 8 categories: TIAM region; Sector; Topic; WMSDs relevance; Work activities; Risk assessment methodology; Results of reassessment and Impact on performance. Finally, the database has been successfully uploaded onto the website (www.TIAM.eu) in order to share knowledge and promote good practices in WMSDs prevention. Collecting good practices based on a collaborative platform for preventing WMSDs will not only help companies improve and maintain healthy and safe working conditions, but will also promote the creation of new solutions in the field of WMSD and injuries prevention.
\end{abstract}

Keywords: Good practice, Work-related musculoskeletal disorders (WMSDs), occupational risk prevention, toolkits, safety and health in workplace

\section{Introduction}

Every four and a half seconds an employee somewhere in a workplace in the EU suffers an accident that forces them to miss work for at least three work days. The number of this category of occupational accidents is very high - more than seven million per year [3].

A lack of effective safety and health protection at the workplace means absences due to accidents and occupational diseases. This not only has a negative effect on the workforce, but flows through detrimentally to the overall economy as well. The enormous costs associated with such work accidents hinder economic growth, because most them will be met by social security systems and public finances [5].
Occupational accidents and diseases impose significant costs on individual companies as well, especially on small and medium enterprises (SMEs) [10]. Therefore ensuring the safety and health of employees generally is in the interests of all regions of TIAM project (Toolkits for hazard identification, risk assessment and prevention of work-related musculoskeletal disorders based on a collaborative platform).

As pointed out within the I4W application: In industrialized countries, work-related musculoskeletal disorders (WMSDs) and injuries are the most common occupational health problems. WMSDs now account for over $50 \%$ of all occupational diseases (with peaks of $85 \%$ and $80 \%$ in Spain and France,

**Corresponding author. E-mail: bing.zhang@upc.edu 
respectively) [12] [17]. They reduce company profitability and add to governments' social costs. Successful WMSD prevention can therefore greatly contribute to creating more and better quality jobs, as has been demonstrated in a number of successful cases in different work sectors (mainly in manufacturing). Moreover, EU-legislation has established new and highly innovative technical standards (EN 1005, ISO 11226/11228) in the area of "physical ergonomics, specifically aimed at protecting the "working population” from biomechanical and organizational risks for WMSDs [1-2].

In general, it is not easy for users to find a suitable tool or strategy for identifying hazards and assessing risks for purposes of WMSDs prevention. Additionally, there are no criteria or guidelines for teaching users how to select the best method for a specific case [10-12] [16]. TIAM project granted by Innovation 4 Welfare (I4W), will provide a high value to enterprises in the participating regions which are Catalonia (ES), Lombardy (IT), South-West Bohemia (CZ) Upper Austria (AU), Estonia (EE), Province Noord-Brabant (NL).

In the first part of the project the partner organizations conducted a Good Practice collection in each of their respective countries. The goal of the collection, besides raising employer awareness, was to become familiar with the national and OSH environments and levels of organization in the participating regions [6-7].

The second part is the development and set of toolkits to help users find the most suitable and effective solution to the problem at hand. The WMSDs prevention toolkits contain not only tools/methods, but also guidelines, processes, checklists and templates for the purpose of hazard identification and risk assessment of WMSDs and injuries [8-9].

There are chosen methods of risk assessment on the basis of previous research. A comprehensive review of the websites and any of the more recent bibliography has been done [13-15].

\section{Method}

In order that potential users benefit fully from TIAM project, the leading participants also focus on collecting successful experience, innovations and examples of Good Practice in WMSDs and injuries prevention in each region [4].

The methods include two steps:

1. Collect existing Good Practice from each region including tools and methods

2. Collect successful experiences and innovations from all the regions
On the other hand, the expected results should help to increase the application of the toolkits. First output of the collecting action is the Matrix. The Matrix of Good Practice shows the ergonomic prevention in depth risk management. This Matrix has been used as a basis for updating regional tools, methods company innovations, etc.

The main feature and innovation of the Matrix means:

1) The various toolkits and Good Practice uploaded by each region can be reviewed and adapted to other regions according to the problem at hand

2) Each region can evaluate and improve the toolkits after adapting and applying them to new applications

3) This collaborative platform is interactive and able to be continually updated even after the project has finished.

Furthermore, the significance of this project is underlined by the breadth of its possible application to companies, industries, and organizations, and by the opportunity of utilization of the results globally.

\subsection{UPC's Good Practice definition}

In order to ensure only good practice (information) that is reliable and meets identified criteria for prevention of work-related musculoskeletal disorders and injuries will be reported, we tried to define and establish criteria for Good practices.

Good Practices are practical successful designs, solutions or practices in the context of legal requirements. The Good Practice procedure is simplified compared to the Best Practice procedure and identify solutions that will improve or prevent errors in the relationship of benefits and investments [18].

Good Practices are case study examples of ergonomic intervention in a workplace of a company or some workplaces in some companies of a regional sector. This definition of Good Practices is developed by UPC as leader partner of TIAM project (UPC_ Universitat Politecnica de Catalunya, Barcelona, Spain).

\subsection{Types of Good Practice}

In order to understand how best to promote innovation, we must have an understanding of existing Good Practices. To gain this understanding, project partners identified Good Practices related to innovation and welfare in each participating region and analysed them based upon:

- The technologies utilized and/or promoted and how they were applied 
- The beneficiaries and targets of the practice

- $\quad$ The regional impact and consistency with regional/EU policies

- $\quad$ The conditions needed to successfully implement and sustain the practice

- The transferability of the practice to other regions

\subsection{Key criteria of Good Practices}

The following 3 steps have been consistently identified as key criteria for a Good Practice solution for prevention of work-related musculoskeletal disorders:

- Adequate initial assessment of the risks associated with manual handling, lifting, pulling and pushing, repeated movements, etc.:

In the risk assessment, the tools and methods based on ISO and EN standards have to be described in detail. And the related risk index has to be calculated.

- Activation and development of a significant and documented intervention to reduce and control the risk technical and/or procedural and/or organization:

The ergonomic intervention may include structural issues such as the optimum arrangement of the workplace, furnishings and layout or the choice of ergonomic tools and equipment and technological aspects.

- Reassessment and post intervention, risk and estimation of the effects induced:

This step is in order to present the achievement of a permanent and identifiable reduction in the risk of harm to workers. The reassessment procedure should apply the same tools and methods as in the initial assessment of risk and hazard for validating the results. The related risk index has also to be calculated.

Additionally, there are optional and specification information to be reported. For instance, direct cost for prevention; impact on performance (quantitative and qualitative) of the production process involved; the good practices should contain sufficient information such that it can be applied where relevant to other European Union Workplaces.

\section{Result}

A good practice matrix of WMSD prevention has been designed and refined during the development of the database.

\subsection{The Good Practice Matrix}

The Good Practice Matrix should give an innovative overview including a "first" picture on how deep OSHA and or from the lead partner forced OCRA standards are used in each country. The matrix should be able to give sector related in-depth answers.

The matrix' main goal is to show an ongoing updateable list of interregional WMSDs activities / outputs / impacts.

This Matrix supports the Good Practices to identify, assess, control, manage and evaluate TIAM's interregional Good Practice collection.

\subsection{Output Good Practice collection within TIAM}

Good Practice report form was sent to each partner via email and each partner has to send back at least 2 Good Practices.

Upper Austria as responsible partner received in sum of 15 Good Practices (Table 1).

Table 1 Regions and number of good practices

\begin{tabular}{|l|c|}
\hline Region & Good Practice examples \\
\hline Cataluña & 1 \\
\hline Lombardy & 1 \\
\hline Tartu & 2 \\
\hline Upper Austria & 2 \\
\hline Bohemia & 9 \\
\hline
\end{tabular}

\subsection{Ergonomic Scope of Good Practices}

Good Practices collected by TIAM are in the following ergonomic scope and have high relevance on WMSDs: Lifting/Carrying; Pushing/Pulling; Repetitive movements; Awkward postures.

However, within the participating regions it can be seen that repetitive movements are the main risk factors in WMSDs. This is a positive understatement to the focus of the TIAM project pointed out by the lead partner UPC (Table 2).

Table 2 Good practices and the ergonomic scope

\begin{tabular}{|c|c|c|c|}
\hline \multicolumn{4}{|c|}{ Good Practices and the ergonomic scope } \\
\hline $\begin{array}{l}\text { Lifting / } \\
\text { Carrying }\end{array}$ & $\begin{array}{l}\text { Pushing } \\
\text { /Pulling }\end{array}$ & $\begin{array}{l}\text { Handling } \\
\text { of low } \\
\text { loads }\end{array}$ & $\begin{array}{l}\text { Handling of } \\
\text { high loads }\end{array}$ \\
\hline 6 & 2 & 9 & 2 \\
\hline
\end{tabular}

\subsection{Tools / Methods:}

We found that the OCRA index or OCRA checklist and OSHA were not well known by all the regions and were not used as national or regional standard for risk assessment and/or additional methods. Especially in company driven prevention activities, EN and ISO based OCRA index or OCRA checklist were not mainly used. However, other innovative 
methods have been found within some companies. For example within HABAU Ltd: According to the Austrian law on occupational safety and health (Arbeitsschutzgesetz) and the decree on manual material handling (Lastenhandhabungsverordnung), an ascertainment of working conditions and of the aptitude of workers is required as a matter of routine (Table 3 ).

The main output of used WMSDs prevention tools or methods within the collection of Good Practice is presented in Table4.

\subsection{Outputs}

In general, the national defined goal to minimize risk effects is reached. In detail, there are many differences in quality and in particular in post interventions and reassessments processes. To point out: Reassessments are not common used. One main reason could be that companies are in line with national rules and laws as soon as they reduce risk effects. There is no prevention foreseen in laws and rules (Table 4).

\subsection{Impact on performance}

The impact on performance includes direct impacts and indirect economic saving besides health awareness (Table 5).

\subsection{Website of TIAM}

The good practice data bank has been uploaded online of TIAM website. This data bank is open to update. The homepage of TIAM website is presented in Figure 1. On the website, the structure of Good practice in prevent of WMSDs can help the users or readers to identify the good practice based on categories easily. The structure of Good practice is depicted in Figure 2.

There are several methods presented on website of TIAM in prevention of WMSDs. Those methods include software tools of OCRA index and checklist, NIOSH Lifting Index (based on NIOSH revised equation), a procedure for collecting manual handling loads in construction industry.

Table 3 Risk assessment tools and methods

\begin{tabular}{|c|c|c|c|}
\hline $\begin{array}{l}\text { Risk } \\
\text { assessment }\end{array}$ & TOOLS & $\begin{array}{l}\text { NORM } \\
\text { ISO / EN }\end{array}$ & Method \\
\hline $\begin{array}{l}\text { OCRA } \\
\text { Checklist (ISO } \\
11228-3 \text { and } \\
\text { EN 1005-5) }\end{array}$ & $\begin{array}{l}\text { Factor Analysis OCRA } \\
\text { Checklist }\end{array}$ & OCRA Checklist & OCRA Checklist \\
\hline $\begin{array}{l}\text { Lead character } \\
\text { method }\end{array}$ & Ergonomic workshops & $\begin{array}{l}\S 64 \text { ASchG, §62 AAV, §4 MSchG, Norms: ÖNORM } \\
\text { A8010, DIN 33402, EN 840, EN 1005, EN ISO 7250, } \\
\text { EN ISO 11064, DIN 33406 }\end{array}$ & $\begin{array}{l}\text { Step by step } \\
\text { measure of lead } \\
\text { characters }\end{array}$ \\
\hline $\begin{array}{l}\text { Lead character } \\
\text { method }\end{array}$ & Lead character analysis & $\begin{array}{l}\S 64 \text { ASchG, §62 AAV, §4 MSchG, Norms: ÖNORM } \\
\text { A8010, DIN 33402, EN 840, EN 1005, EN ISO 7250, } \\
\text { EN ISO 11064, DIN 33406 }\end{array}$ & $\begin{array}{l}\text { Step by step } \\
\begin{array}{l}\text { measure of lead } \\
\text { characters }\end{array}\end{array}$ \\
\hline & Nordic Questionnaire & not defined & validation method \\
\hline
\end{tabular}

Table 4 Risk effects, post interventions and reassessment

\begin{tabular}{|c|c|c|}
\hline Risk Effects & $\begin{array}{l}\text { Post } \\
\text { Interventions }\end{array}$ & Reassessment \\
\hline $\begin{array}{l}\text { 1.Technical actions reduced from } 50 \text { to } 24 \text {. } \\
\text { 2.Shoulder flexion and abductions reduced. } \\
\text { 3.Elbow Flexion/Extension reduced to less than 5\% }\end{array}$ & $\begin{array}{l}\text { modification in breaks or length of } \\
\text { workday }\end{array}$ & \\
\hline $\begin{array}{l}\text { Found practical and individual solutions and implementation } \\
\text { in the daily work life }\end{array}$ & ongoing & ongoing \\
\hline $\begin{array}{l}\text { Found practical and individual solutions and implementation } \\
\text { in the daily work life }\end{array}$ & $\begin{array}{l}\text { Development of the activity catalogue to } \\
\text { assess the risk index on a standardized } \\
\text { procedure }\end{array}$ & ongoing \\
\hline reduced & Workplace optimized & \\
\hline not examined & elevator system and a suitable trolley & \\
\hline
\end{tabular}

Table 5 Direct and indirect impacts

\begin{tabular}{|l|l|l|}
\hline Direct impacts & Indirect economic saving & Health awareness \\
\hline & $\begin{array}{l}\text { Decrease in worker absenteeism } \\
\text { due to shoulder and elbow pain }\end{array}$ & Workplace health promotion \\
\hline Positive image & $\begin{array}{l}\text { - Less individual work accidents } \\
\text { - Costs of staff illness were minimized }\end{array}$ & $\begin{array}{l}\text { New catalogue of health and } \\
\text { safety activities }\end{array}$ \\
\hline & & \\
\hline & Minimized Absenteeism & \\
\hline $4.000,-$ Investment & $\begin{array}{l}\text { Develop a rehabilitation plan with a focus on upper extremity } \\
\text { To make new shelf and special trolley }\end{array}$ & \\
\hline
\end{tabular}




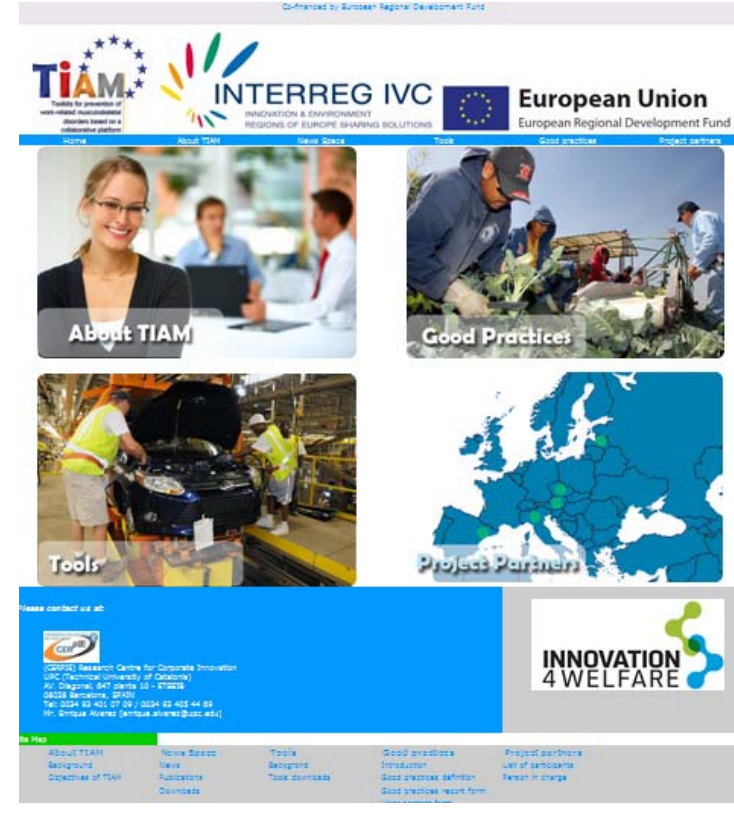

Figure 1 Homepage of TIAM project( www.TIAM.eu) risks. This confirms recent policy initiatives to include self-employed workers into the scope of OSH prevention.

- Workers are generally exposed to several WMSD risk factors. A new approach is needed to address multiple risks in research, workplace action and health care.

- European data should always be compared and complemented with national, sectoral, group-, gender- and age-related studies. They provide a better insight and allow for an earlier identification of emerging issues.

- Current harmonised monitoring tools provided limited data on some WMSD and risk factors. Some national data systems could serve as a model for further development, for example on cumulative disease figures and multifactor assessment.

- Recognition practices still vary considerably between member states, but overall more WMSD are being recognised. A major obstacle is the difficulty of the current monocausality approach in addressing the multifactor aetiology of WMSD.

TIAM Good Practices

to identify, assess, control, manage and evaluate workplace hazards of WMSDs

\begin{tabular}{|c|c|c|c|c|c|c|c|c|c|c|c|c|c|c|}
\hline \multirow{2}{*}{$\begin{array}{c}\text { TLAM } \\
\text { Regions }\end{array}$} & \multirow[t]{2}{*}{ Sector } & \multirow[t]{2}{*}{ Topic } & \multirow{2}{*}{$\begin{array}{l}\text { WMSDs } \\
\text { relevance }\end{array}$} & \multicolumn{4}{|c|}{ Work activities } & \multicolumn{3}{|c|}{ Risk Assessment Methodology } & \multirow{2}{*}{$\begin{array}{c}\text { Results of } \\
\text { Reassessment }\end{array}$} & \multicolumn{3}{|c|}{ Impact on performance } \\
\hline & & & & $\begin{array}{l}\text { Lifting/ } \\
\text { Carrying }\end{array}$ & $\begin{array}{l}\text { Pushing / } \\
\text { Pulling }\end{array}$ & $\begin{array}{c}\text { Repetitive } \\
\text { movements }\end{array}$ & $\begin{array}{l}\text { Akward } \\
\text { postures }\end{array}$ & Method/Tool & $\begin{array}{c}\text { NORM } \\
\text { ISO / EN } \\
\text { References }\end{array}$ & $\begin{array}{c}\text { Risk } \\
\text { assessment } \\
\text { (Yes or No) }\end{array}$ & & $\begin{array}{l}\text { Direct } \\
\text { impacts }\end{array}$ & $\begin{array}{l}\text { Indirect } \\
\text { impacts }\end{array}$ & Others \\
\hline
\end{tabular}

Figure 2 Structure of Good practice

\section{Discussion}

Here are some highlighted findings added with European key findings:

- Detailed data extraction and analysis is needed in order to identify groups at risk and have a correct perception of the situation in specific industrial sectors.

- Cumulative figures of WMSD would provide a better picture of the actual situation.

- WMSD and exposure to WMSD risk factors are increasing in younger working populations.

- Women are also considerably exposed, but the effects are still under recognised.

- $\quad$ Service professions are still not regarded as physically strenuous, a fact that is reflected in WMSD recognition figures, and in contradiction with data on exposures.

- Work-related lower limb disorders are insufficiently addressed by monitoring, prevention, compensation and rehabilitation.

- $\quad$ Self-employed workers appear to be more affected by WMSD and exposed to WMSD

\section{Conclusion}

Regarding to the technical and scientific advances, three internal documents have been developed for collecting good practices in all the 5 regions within TIAM project:

- General specifications of good practices to fulfill. In order to ensure only good practice (information) that is reliable and meets identified criteria for prevention of work-related musculoskeletal disorders and injuries was reported, we tried to define and establish criteria for Good practices.

- Application form to report good practices. This document has been supplemented with the reporting of a real good practice, to use as an illustrative example.

- $\quad$ TIAM questionnaire related to regional policy. This questionnaire seeks to identify good practices in terms of regional policy in the prevention of work-related musculoskeletal disorders (WMSD) by asking several important questions to all regions participating in TIAM projects. 
A good practice matrix of WMSD prevention has been designed and refined during the development of the database based on 15 Good practices collected from 5 European regions within TIAM project.

\section{Future work}

The main future work of TIAM project will focus on how to refine the database of good practice and make the website interactive with users.

The long-term objective of TIAM project is that the website will permit a valid assessment of the workplace factors for identify WMSDs in the future and consequently may also be used for development of prevention measures. Hence, the TIAM project will significantly enhance health care, life quality and productivity, effectively reduce sick leave and economic/social costs connected to work related muscular disorders and injuries.

\section{Acknowledgement:}

It would not have been possible for us to write this paper without the help and support of Prof. Enrico Occhipintiand and Dr. Natale Battevi from Dipartimento Area della Medicina Preventiva, U.O. CEMOC (Milano).

\section{References:}

[1] CEN (2003). EN 1005-2: Safety of machinery. Human physical performance. Manual handling of machinery and component parts of machinery

[2] CEN (2007). EN 1005-5: Safety of machinery. Human physical performance. Risk assessment for repetitive handling

[3] Fourth European Working Conditions Survey; European Foundation for the Improvement of Living and Working Conditions, Dublin

[4] Guidelines on the collection, evaluation, and dissemination of good practice information on the internet, Version 07, Bilbao, July 2000. European Agency for Safety and Health at Work. http://osha.europa.eu/en

[5] IOSHA Survey Report; based on the survey conducted within the framework of the project "IOSHA Improving Occupational Safety and Health Awareness of Employers and Employees in CEE”

[6] Lifting postures - Facts and figures; National Report: Austria

[7] Lifting postures - Facts and figures; National Report: Germany

[8] Macdonald, W. and Evans, O. (2006). Report of research on the prevention of work-related musculoskeletal disorders stage 1 - Literature Review. ISBN: 0642326436

[9] Toolbox Version 1.1: Instrumente zur Erfassung und Bewertung psychischer Belastungen

[10] Work-related musculoskeletal disorders in the EU Facts and figures

[11] Work-related musculoskeletal disorders - Facts and figures - Czech Republic

[12] Work-related musculoskeletal disorders - Facts and figures” - Spain
[13] Waters, T. R. , Lu, M. -L. and Occhipinti, E.(2007) 'New procedure for assessing sequential manual lifting jobs using the revised NIOSH lifting equation', Ergonomics, 50: 11, $1761-1770$

[14] Waters, T.; Occhipinti, E.; Colombini, D.; AlvarezCasado, E.; Hernandez-Soto, A. The variable lifting index (VLI): a new method for evaluating variable lifting tasks using the revised NIOSH lifting equation. Proceedings of the 17th Triennial Congress of the International Ergonomics Association, August 9-14, 2009, Beijing, China. Taiwan, ROC: International Ergonomics Association, 2009 Aug;1-3

[15] Winkel, J., \& Mathiassen, R. (1996). Editorial: A model for solving work related musculoskeletal problems in a profitable way. Applied ergonomics. Vol 27. No. 2. 71-77.

[16] Womack, S., Armstrong, T., Liker, J. (2009). Lean job Design and musculoskeletal Disorder Rosk: A two Plant Comparison. Human Factors and Ergonomics in manufacturing. Vol. 19. 279-293.

[17] Work-related musculoskeletal disorders_facts and figures National report_Spain.pdf, EU-OSHA European Agency for Safety and Health at Work 2010.

[18] www.osha.europa.eu (Good practice information_provided by EU-OSHA) http://osha.europa.eu/en/practical-solutions/en_goodpractice_2009.pdf 